\title{
Effectiveness of Nutrition Education on Nutrient intake and Nutrition Status of infants in Ondo State, Nigeria
}

\author{
Akinrinmade $\mathrm{R}^{1 *}$, Njogu $\mathrm{E}^{2}$ and Ogada $\mathrm{I}^{3}$ \\ ${ }^{1}$ Rufus Giwa Polytechnic, Nigeria \\ ${ }^{2}$ Kenyatta University, Kenya \\ ${ }^{3}$ St Francis Xavier University, Canada \\ *Corresponding author: Akinrinmade R, Nutrition and Dietetics Department, Rufus Giwa Polytechnic, Owo, Ondo State, Nigeria. \\ To Cite This Article: Akinrinmade R. Effectiveness of Nutrition Education on Nutrient intake and Nutrition Status of infants in Ondo State, \\ Nigeria. Am J Biomed Sci \& Res. 2019 - 3(2). AJBSR.MS.ID.000642. DOI: 10.34297/AJBSR.2019.03.000642
}

Received: April 22, 2019 | Published: May 24, 2019

\begin{abstract}
Malnutrition during infancy has been linked to lack or low knowledge of appropriate feeding practices of the caregivers. This study determined the effectiveness of nutrition education on Minimum Acceptable Diet (MAD) as an indicator of complementary feeding to achieve the nutrient intake and nutrition status of infants (6-11 months) in Ondo State, Nigeria. The study was a cluster randomized controlled trial design, whereby the participants were assigned to two groups. One intervention and one control group in a ratio of 1:1. The sample size was 142 for intervention group and 142 for the control group. Nutrition education on MAD was carried out among the caregivers in the intervention group and the control group received no nutrition education. The nutrition education was based on dietary diversity and meal frequency putting into consideration the hygiene practices. To determine the nutrient intake of the infants, data was collected from caregivers as the infants progressed in age using questionnaires. nutrient intake of the infants was assessed using 24-hr dietary recall. Data were analyzed using SPSS version 22.0. From the analysis, there was no significant difference in demographic and socio-economic status of the caregivers and Nutri-survey software for the nutrient intake. There was no significant difference in the complementary food intake of the infants as intended by the caregivers at the baseline. At the midline and the endline after the nutrition education, the nutrients intake of the infants in the intervention group was higher than the nutrient intake of the infants in the control group as analyzed using nutri-survey. Energy intake of infants in the intervention group was higher both at the midline (259kcal \pm 20.67$)$ and at the endline $(366.7 \mathrm{kcal} \pm 23.03)$ than those in the control group both at the midline $(121.1 \mathrm{kcal} \pm 17.05)$ and the endline $(212 \mathrm{kcal} \pm 22.04)$. There was a significant difference in WAZ ( $t$. test; $p=0.001$ ), WAZ ( $t$. test; $p=0.001$ ) but no significant difference in HAZ (t. test; $p=0.049$ ). There was an association between meal frequency and under nutrition (AOR: 0.489 (0.26-0.92) p-value; 0.027, dietary diversity and stunting (AOR:1.493 (1.251.80) p-value; 0.001)
\end{abstract}

Keywords: Nutrient intake; Nutrition status; Infants; Caregivers; Nutrition education

\section{Introduction}

The minimum adequate diet (MAD) can only be achieved when the infant feeding recommendations on feeding frequency and dietary diversity are met [1]. Children receiving the minimum acceptable diet (met minimum meal frequency and minimum dietary diversity) were $11 \%$ in sub-Sahara Africa, $9 \%$ in West and Central African countries and $10 \%$ in Nigeria [2]. The report of the Nigerian National Demographic and Health Survey [3] indicated that only $11 \%$ of the breastfed infants received complementary foods from at least four food groups.

The services of Nigerian government through the use of National infant feeding policy are the Informative, Educative and Communicative (IEC) materials on breastfeeding, food diversification, responsive feeding and hygiene practices that are available in the community health facilities. The Community Health Extension Workers needed to be trained by the nutritionist with these IEC materials for effective teaching and explanation of the materials to the caregivers. The strategy for achieving IYCF according to must be followed in the health facilities in order to achieve adequate infant feeding practices [4].

Under nutrition of protein and energy-giving foods contributed to $45 \%$ of death, among children less than five years of age in evidence-based research carried out in 34 countries [5]. In the developing countries, malnutrition has been proved to be responsible for over $41 \%$ of the deaths among children 6 to 24 months of age [6]. 
Prevalence of malnutrition increases during the period of complementary feeding in many countries [7]. In Nigeria, moderate wasting was higher among infants aged 6-11 months with prevalence of $21.3 \%$ and this was associated with complementary feeding practices among the caregivers [8]. It was showed that $32.9 \%$ of infants were moderately stunted and $19.4 \%$ were moderately underweight [9]. Malnutrition rate, especially the acute malnutrition is high in Ondo State among the infants. It was also revealed that $26 \%$ of the children less than five years were stunted while $43 \%$ were moderately wasted in Ondo State [10].

In Ondo State, Nigeria which is the study area, $70 \%$ of the infants received pap (sorghum-based fluid diet) monotonously without food diversification [11]. The author further stated that poor knowledge and attitude to complementary feeding contributed to poor infant feeding, whereby the caregivers fed infants with gruel from sorghum only, without varying the food items for complementary feeding which lead to malnutrition in the State.

\section{Research Objectives}

To determine the nutrient intake of the infants age 6-11monts. To identify changes in the nutrition status of the infants as the infants progressed in age after the nutrition education program

\section{Material and methods}

\section{Sampling frame}

The population of caregivers with infants aged 5 months to 5 months and 3 weeks

Sample size: The study applied Chan, (2003) formulae for continuous assessment of two independent samples. Type II error and power set at two-sided 5\% with a study power of $90 \%$.

$$
\begin{aligned}
& \mathrm{m}=2 \mathrm{C}+1 \\
& \delta^{2} \\
& \mathrm{~m}=\text { the desired sample size } \\
& \mathrm{c}=\text { Power of the study }(10.5 \text { for } 90 \%) \\
& \delta=\text { the standard effect size } \\
& \sigma=\text { common standard deviation }(0.5) \\
& \delta=(\mu 2-\mu 1) \\
& \sigma
\end{aligned}
$$

where $\mu 2-\mu 1=$ mean of the two groups,

$\mu 1=30 \%$ adequate complementary feeding practices in Nigeria (Olatona et al., 2014) the existing literature

$$
\begin{aligned}
& \mu 2=\text { absolute improvement }(20 \%)=50 \% \\
& \delta=0.2 / 0.5=0.4 \text { and for a } 90 \%, \text { it is calculated thus } \\
& \mathrm{m}=(2 \times 10.5)+1 \\
& (0.4 \times 0.4)=132.25
\end{aligned}
$$

Hence $132 \times 2$ was needed to cater for clustering effect, which is equal to 264 participants. Also, $10 \%$ was added for attrition/ loss to follow-up which totals to $264+26.4=290$ for both groups. Meanwhile, 6 caregivers were lost to follow up and the study ended with 284 caregivers.

Sampling techniques: Purposive sampling technique was used due to the report of existing literature in Owo Local government. Thereafter randomization was carried out to select the basic health centers where the mothers usually go for weekly routine of infants' immunization and where they visit for medical counseling about the infants.

\section{Target population}

Caregivers with infants less than six months of age and about to start complementary feeding or has stated earlier but the infants is yet to be six months of age.

\section{Materials}

Interviewer administered questionnaire

24Hrs dietary recall questionnaire moderated by [12]

24Hrs dietary recall questionnaire moderated by [13]

Infant-o-meter (UNICEF model S0114530)

UNICEF infants weighing scale (model ws2002)

Food models (locally made at Rufus Giwa Polytechnic, Nutrition and Dietetics Department for dietary intake assessment)

Kitchen weighing scale (EMK 5004A Kitchen 1kg. accuracy 5g weighing scale)

\section{Study design}

It was a cluster randomized controlled trial whereby the basic health centers were randomized into two groups. One was the intervention group and the other was the control group. The basic health centers not the caregivers were randomised into groups because if the caregivers were randomised, some may be randomised into basic health center that is far from their location. The caregivers who participated willingly and were available throughout the period of the research, which lasted for 6-7months per participant depending on the period of registration were the eligible participants chosen for the study.

Interviewer administered questionnaire was used to assess information on socio-demographic and socio-economic status of the caregivers at baseline to determine similarities among the two groups. A 24 Hrs dietary recall questionnaire moderated by [12] was used to collect data on what the infant was fed in the previous 24 hours and this tool was used to determine the complementary feeding practices among the caregivers for six months to determine the monthly MAD.

Another $24 \mathrm{hr}$ questionnaire moderated by [13] was used to collect information on quantity of the food items consumed by the infants and the time that particular food was consumed, and the quantity taken at a particular time. It was administered to each participant at each follow up point to determine the nutrient intake of the infants both in the intervention and the control group. A 
kitchen weighing scale, food models and price of the food where necessary were used to determine the quantity of food items consumed. Section D: Anthropometrics assessment; Length was taken and recorded to the nearest $0.1 \mathrm{~cm}$ and weight was recorded to the nearest $0.1 \mathrm{~kg}$

\section{Data management}

Training was carried out among the research assistants on interview techniques, research ethics and how to carry out anthropometric assessments of the infants. The interviewers were interviewed with English language written questionnaires but were interpreted to the participants in Yoruba language in the situation where the participants could not respond satisfactorily to the questions. This was guided by questions asked by the participants during interview and training as observed during the pilot survey.

Community Health extension Workers (CHEWs) were trained on MAD for complementary feeding Using "Participants' manual on complementary feeding, counseling a training course" by [14]. The CHEWs were trained for five days on the nutrition education outline as prepared to be used for the caregivers. Other training received by the CHEWs was how to carry the participants along during training, for the training to be a participatory one.

The caregivers were trained on dietary diversity, meal frequency and hygiene practices (washing of hands before and after feeding the infants). This was achieved for three consecutive Saturdays. Saturday was chosen due to the understanding of the peoples' way of life during the pilot study.

Follow-up and management of appointment: After the recruitment and training, the caregivers were followed up during the programme. The telephone number of the caregiver or the father or anyone in the household that owned mobile phone and the home address were registered with the researcher, CHEW and the enumerator in charge of that zone as allocated by the researcher Two days to and on the eve of visitation day, the enumerator allocated to the area would call to remind the caregivers about the visitation day. The questionnaire was administered again by the enumerator, and on the date of the interview, the age of the

Results

Comparison of socio-demographic and economic characteristics of the caregivers who completed and those lost to study

\begin{tabular}{|c|c|c|c|}
\hline \multirow[b]{2}{*}{ Variables } & \multicolumn{3}{|c|}{$\%$ of caregivers by groups } \\
\hline & $\begin{array}{l}\text { Caregivers who completed the pro- } \\
\qquad \operatorname{gram}(\mathrm{N}=284)\end{array}$ & $\begin{array}{l}\text { Caregivers who lost to follow up } \\
\qquad(\mathrm{N}=142)\end{array}$ & $\begin{array}{c}\text { Chi-square } \\
\text { p-value }\end{array}$ \\
\hline \multicolumn{4}{|c|}{ Socio-demographic characteristics } \\
\hline Mean caregivers 'age \pm SD & $26.2 \pm 4.2$ & $25.4 \pm 3.7$ & 0.405 \\
\hline Mean caregivers' parity \pm SD & $2.9 \pm 1.7$ & $2.4 \pm 1.3$ & 0.064 \\
\hline \multicolumn{4}{|c|}{ Ethnicity } \\
\hline Yoruba & $216(76.1)$ & $4(66.7)$ & \\
\hline ssIbo & $48(16.9)$ & $1(16.7)$ & \\
\hline Ebira & $20(7.0)$ & $1(16.7)$ & 0.056 \\
\hline
\end{tabular}

infants in months was recorded against the food intake and the infant nutritional status was assessed and recorded for that month. The individualised counselling during follow up was done by the CHEW. This was done on different days depending on the visitation day of each participant at home and at times when not available at home, any convenient and available place was always chosen as an alternative.

\section{Analysis}

Statistical Package for the Social Sciences (SPSS) version 22.0 was used to analyse data. Descriptive statistics in terms of percentages and frequencies were generated for participants' socioeconomic and demographic characteristics, infant characteristics and infant feeding intention by the caregivers as well as the infants feeding history at the baseline. Inferential statistics like Chi-square were used to establish the significant relationships between categorical data such as sex, marital status of the caregivers.

Nutri-survey (2007) software was used to analyse nutrient intake especially the iron content of the complementary foods for the infants. Local foods were computed into Nutri-survey software using $[15,16]$. This was recorded based on Recommended Dietary Allowance (RDA)/ Adequate Intake (AI). It was analysed individually and also on group basis, to determine the effect of the intervention on the complementary feeding practices.

ENA for SMART was used to analyse anthropometrics' data based on [17]. The Z-score was used to determine weight-forage, length-for-age and weight-for-length z-scores, -2z score was considered malnutrition, and $<-3 \mathrm{z}$ score as severe malnutrition while z-score of $>-2$ was considered as normal nutrition status. T-test and Mean (SD) was carried out to determine variation in nutrition status and the mean difference.

\section{Logistics and ethical considerations}

Ethical clearance was obtained from Ondo State Health Research Ethics Committee (OSHREC). Letter of introduction to the coordinator of Owo LGA, BHCs was obtained from Ondo State Primary Health Care Development Board (OSPHCDB), Nigeria. 


\begin{tabular}{|c|c|c|c|}
\hline \multicolumn{4}{|c|}{ Marital status } \\
\hline Married & $272(95.8)$ & $4(66.7)$ & \multirow{5}{*}{0.342} \\
\hline Single & $4(1.4)$ & $0(0.0)$ & \\
\hline Divorced & $1(0.7)$ & $0(0.0)$ & \\
\hline Separated & $6(2.1)$ & $1(07)$ & \\
\hline Widowed & $0(0.0)$ & $1(0.7)$ & \\
\hline \multicolumn{4}{|c|}{ Source of household income } \\
\hline Parental & $7(2.1)$ & $0(0.0)$ & \multirow{5}{*}{0.713} \\
\hline Government/Civil servant & $8(2.8)$ & $0(0.0)$ & \\
\hline Farming & $31(11.3)$ & $2(33.3)$ & \\
\hline Business & $16(6.3)$ & $1(16.7)$ & \\
\hline Spouse support & $216(76.1)$ & $3(50.0)$ & \\
\hline \multicolumn{4}{|c|}{ Mean average income in } \\
\hline $\mathrm{N} \pm \mathrm{SD}$ & $27,640 \pm 30.425$ & $25,738 \pm 12.327$ & 0.076 \\
\hline No formal education & $7(2.5)$ & $0(0.0)$ & \\
\hline Primary school & $39(13.4)$ & $2(33.3)$ & \\
\hline Secondary school & $162(55.6)$ & $3(50.0)$ & \\
\hline Tertiary & $31(10.6)$ & $0(0.0)$ & 0.072 \\
\hline
\end{tabular}

There was no significant difference in the characteristics of the caregivers that completed and those who were lost to follow up in this study (Table 1). The total participants were 290 caregivers and 6 caregivers were lost from follow up. The socio-economic characteristics of the caregivers were similar. There was no significant difference in the income earn monthly in both groups $(\chi 2: 1.134 ; p=0.076)$.

\section{The effect of nutrition education on complementary feeding practices of the caregivers}

\begin{tabular}{|c|c|c|c|c|c|c|}
\hline CBF practices & Baseline & p-value & Midline & p-value & Endline & p-value \\
\hline \multicolumn{7}{|c|}{ Meal Frequency } \\
\hline \multicolumn{7}{|c|}{ 6-8 Months } \\
\hline \multicolumn{7}{|c|}{ 9-11 Months } \\
\hline $\mathrm{RR}(\mathrm{CI})$ & $0.97(0.94-1.01)$ & 0.857 & 8.13 (3.12-21.19) & $0.001^{*}$ & $3.41(2.36-5.22)$ & $0.001^{*}$ \\
\hline \multicolumn{7}{|c|}{ Dietary Diversity $(\geq 4)$} \\
\hline $\mathrm{RR}(\mathrm{CI})$ & $1.00(0.81-1.25)$ & 1 & 7.89 (4.47-13.92) & $0.001^{*}$ & $6.60(4.43-8.84)$ & $0.001^{*}$ \\
\hline \multicolumn{7}{|c|}{ Minimum Acceptable Diet } \\
\hline $\mathrm{RR}(\mathrm{CI})$ & $0.96(0.75-1.25)$ & 1 & $6.42(2.42-18.33)$ & $0.001^{*}$ & $3.13(2.53-5.16)$ & $0.001^{*}$ \\
\hline
\end{tabular}

The caregivers in the intervention group were (RR: 8.13; CI: 3.12-21.19; $\mathrm{p}=0.001) 8$ times more likely to feed the infant with minimum meal frequency than the caregivers in the control group at the midline and 3.4 times at the endline (RR:3.41; CI: 2.36-5.22; $\mathrm{p}=0.001)$. The result showed that caregivers in the intervention group were 8 times (RR: 7.89; CI: (4.47-13.92; P=0.001) more likely to feed their infants a diversified diet in terms of the complementary foods at midline and 6.7 times at the endline (RR: 6.66; CI: 4.438.84; $\mathrm{p}=0.001$ ). Feeding the infants with minimum acceptable diet was 6.4 times more likely among the caregivers in the intervention group (RR:6.42; CI: 2.42-18.33; $\mathrm{p}=0.001)$ at the midline and 3 times more likely at the endline (RR: 3.13; CI: 2.53-5.16; $\mathrm{p}=0.001$ ). This shows that the infants in the intervention group were more like to meet the meal acceptable diet requirement compared to the infants in the control group, both at the midline and at the endline of the study (Table 2).

\section{Effect of nutrition education on nutrient intake of the infants at midline and endline by study groups}

Nutrient intake was analysed using nutri survey software and there was a significant difference between the two groups for all nutrients considered. Energy intake was higher among infants in the intervention group than the control group both at the midline $(259.0 \pm 20.67 \mathrm{Kcal} /$ day and $121.1 \pm 17.05$ respectively) and at the endline $(366.7 \pm 23.03 \mathrm{Kcal}$ and $212 \pm 22.04 \mathrm{Kcal}$ for intervention group and control group respectively). Similarly, significant 
differences were found in the mean iron intake assessed both at the midline $(8.0 \pm 0.91 \mu \mathrm{g}$ and $6.6 \pm 0.28 \mu \mathrm{g})$ and at the endline $(12.3 \pm 0.01 \mu \mathrm{g}$ and $8.2 \pm 0.11 \mu \mathrm{g})$ between the intervention and control group respectively. Vitamin $\mathrm{C}$ was highly consumed at the

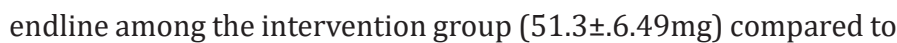
the control group $(12.0 \pm 2.65 \mathrm{mg})$ and it was significantly different $(\mathrm{p}<0.001)$, (Table 3).

Table 3: Effect of nutrition on nutrients intake of the infants at midline and endline by study groups.

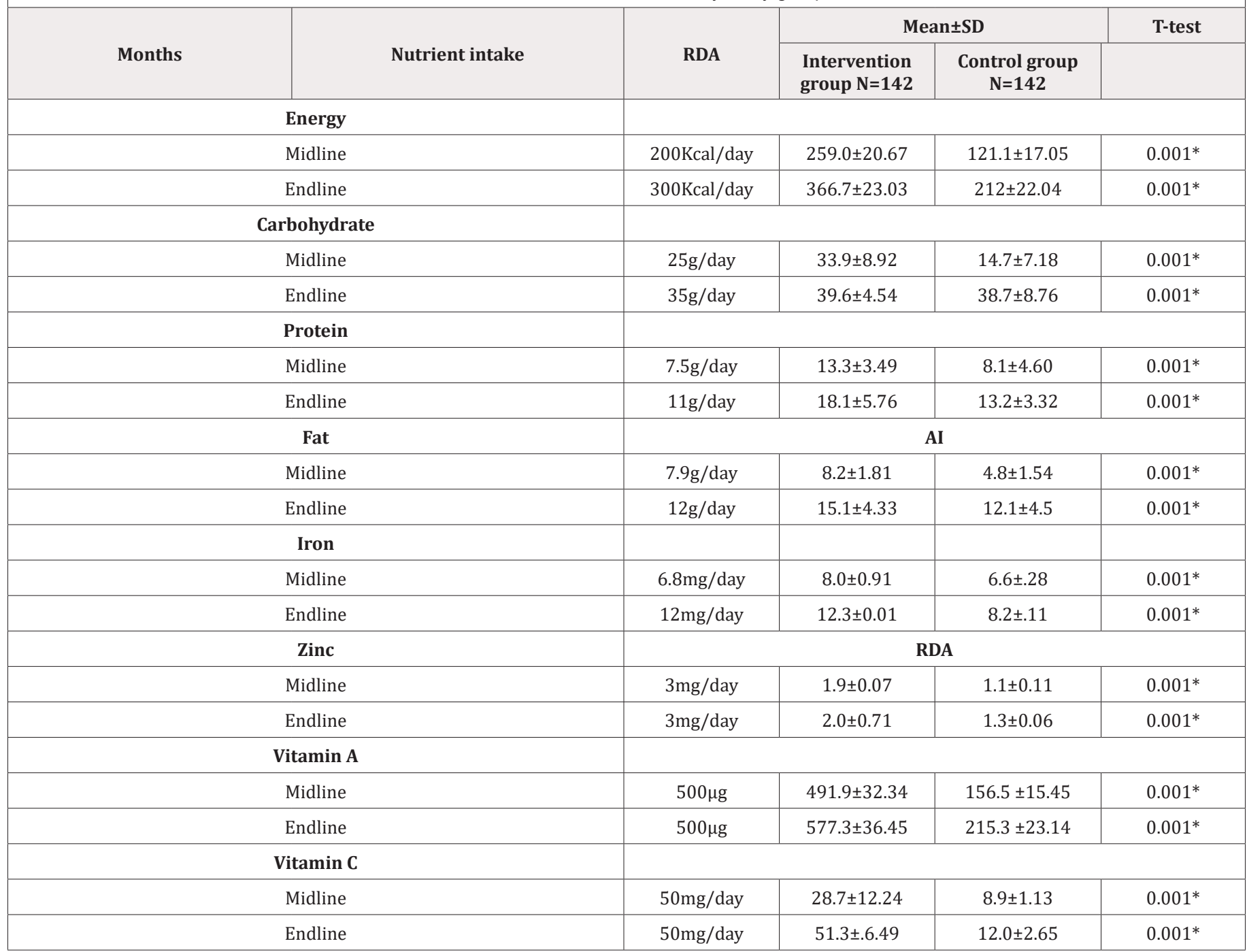

*using Nutri-survey 2007; *significantly different at $\mathrm{P}<0.05$

\section{The influence of nutrition education on nutrition status of the infants by study groups}

Table 4: The influence nutrition education on the nutrition status of the infants by study group.

\begin{tabular}{|c|c|c|c|c|c|c|c|}
\hline Variables & Group & Mean \pm SD & (P-value) & Midline (142) & $P$-value & Endline (142) & p-value \\
\hline \multirow{2}{*}{ WAZ } & Intervention & $-1.59(0.63)$ & \multirow{2}{*}{0.16} & $-0.88(0.70)$ & \multirow{2}{*}{$0.001^{*}$} & $-0.77(0.80)$ & \multirow{2}{*}{$0.001^{*}$} \\
\hline & Control & $-1.48(0.66)$ & & $-1.65(0.70)$ & & $-2.04(0.71)$ & \\
\hline \multirow{2}{*}{ HAZ } & Intervention & $-1.47(0.65)$ & \multirow{2}{*}{0.147} & $-1.46(0.64)$ & \multirow{2}{*}{0.195} & $-1.47(0.65)$ & \multirow{2}{*}{0.049} \\
\hline & Control & $-1.57(0.63)$ & & $-1.48(0.64)$ & & $-1.49(0.63)$ & \\
\hline \multirow{2}{*}{ WHZ } & Intervention & $-1.47(0.80)$ & \multirow{2}{*}{0.161} & $-0.57(1.08)$ & \multirow{2}{*}{$0.001^{*}$} & $-0.46(1.01)$ & \multirow{2}{*}{$0.001^{*}$} \\
\hline & Control & $-1.48(0.81)$ & & $-1.58(0.84)$ & & $-1.91(0.83)$ & \\
\hline
\end{tabular}

*significant at $p<0.05$

The difference in the nutrition status of the infants was computed and analyzed using a paired sample t-test statistic to determine the mean and standard deviation. At the baseline, mean WAZ score was $-1.59 \pm 0.63$ and $-1.48 \pm 0.66$ and there was no

significant difference ( $\mathrm{t}$-test; $\mathrm{p}=0.160$ ) for intervention and control respectively. This later changed to $-0.77 \pm 0.80$ and $-2.04 \pm 0.71$ at the endline and there was a significant difference ( $\mathrm{t}$-test; $\mathrm{p}=0.001$ ). There was also change in the baseline in HAZ scores $-1.47 \pm 0.65$ and 
$-1.57 \pm 0.63$ which had no significant difference ( $t$-test; $\mathrm{p}=0.147$ ) for intervention and control a change was later determined in the mean scores at the endline but there was no significant deference using the t-test $(p=0.049)$. The result of weight for height showed that at the baseline there was no significant difference ( $\mathrm{t}$-test; $\mathrm{p}=0.161$ ) while at the endline the change in the WHZ scores was significant (t-test; $\mathrm{p}=0.001$ ), (Table 4).

\section{Relationship between complementary feeding practices and the nutrition status}

Table 5: Relationship between complementary feeding practices and the nutrition status.

\begin{tabular}{|c|c|c|c|}
\hline Variables & Adjusted Odd Ratio & $95 \%$ CI & p-value \\
\hline \multirow{3}{*}{ Meal frequency } & 0.489 & Underweight (0.26-0.92) & $0.027^{*}$ \\
\hline & 0.404 & Stunting (0.22-0.73) & $0.003^{*}$ \\
\hline & 0.435 & Wasting (0.24-0.81) & $0.008^{*}$ \\
\hline \multirow{2}{*}{ Dietary diversity } & 1.399 & Underweight (1.71-2.64) & $0.037^{*}$ \\
\hline & 1.493 & Stunting (1.25-1.80) & $0.001^{*}$ \\
\hline \multirow{3}{*}{ Minimum acceptable diet } & 3.131 & Wasting (2.36-5.34) & $0.001^{*}$ \\
\hline & 2.263 & Underweight (1.28-2.46) & $0.001^{*}$ \\
\hline & 2.742 & Stunting (4.27-8.45) & $0.001^{*}$ \\
\hline
\end{tabular}

${ }^{*}$ significant at $p<0.05$

A logistic regression model was carried out among the complementary feeding practices variables used for the nutrition education and the nutrition status of the infants to determine the relationship of the complementary feeding variables on the nutrition status variables. Minimum meal frequency was associated with underweight (AOR: 0. 489; CI: 0.26-0.92; $\mathrm{p}=0.027$ ), stunting (AOR:0.404; CI:0.22-0.73 p=0.003) and wasting (AOR: 0.435; CI:0.24-0.81; $\mathrm{p}=0.008)$. Additionally, MAD was associated with wasting (AOR:3.13; CI:2.36-5.34; p=0.001) and underweight (AOR:2.26: CI:1.28-2.46; p=0.001), (Table 5).

\section{Discussion}

The caregivers in both study groups were people living in the rural communities; with similar characteristics in age, parity, living conditions, marital status, educational level and income level. The caregivers were women of age between 16 and 37 years. This corroborates the report of [18] on Nigerian women of child bearing age. The report stated that child bearing age of Nigerian women ranges from 29.5 years in 1970 to 29.8 years in 2015 .

The present study showed the effect of nutrition education which improved the caregivers' complementary feeding practices. Prior to the commencement of nutrition education at the baseline, there was no significant difference in the intention of the caregivers in the two groups on meal frequency and dietary diversity

Minimum meal frequency was achieved by the infants in both groups at 6 to 8 months but there was a significant difference in meal frequency between the infants in the intervention group and those in the control group both at 6-8 months and at 9-11 months. The percentage of infants who received the minimum meal frequency increased as the infants increased in age both in the intervention and in the control group. This was similar to the findings of [19] which revealed that meal frequency increased according to the age of children study in South eastern of Ethiopia.

The meal frequency during Illness was significantly different among the caregivers In the two groups. The caregivers in the intervention group increased the meal frequency during the study compared to the caregivers in the control group

Dietary diversity during complementary feeding was also achieved among the caregivers in the intervention earlier at midline of the study than the caregivers in the control group. The effect of the knowledge of the caregivers in the intervention group was noticeable in the minimum dietary diversity achieved during the feeding practices. There were a higher number of infants who were fed on minimum dietary diversity in the intervention group than in the control group. This study was in line with the study of [20], which showed significant difference between dietary diversity, meal frequency and feeding infants with iron containing foods among caregivers in the intervention group and those in the control group in Uganda. Furthermore, [21] revealed that nutrition education improved dietary diversity among caregivers of infants between 6-23 months in Malawi. Also, [22] showed that nutrition education is a catalyst for improving dietary diversity among caregivers in Lilongwe, Malawi. The improvement in complementary meal frequency and dietary diversity in the intervention group could be linked to the knowledge acquired during nutrition education.

The outcome of the feeding practices after the nutrition education on Minimum meal frequency and Minimum dietary diversity showed that dietary intake of the nutrients was higher among the infants in the intervention group than the control group. Consumption of iron rich foods was high among the infants in both groups and this agrees with the [23] reports on consumption of iron rich foods in South-West Nigeria. The report revealed that $60.1 \%$ of infants in this geo-political zone consumed iron rich foods. Despite the high rate of consumption of iron rich foods in both groups, there was a wide margin of iron rich foods intake between the infants in the intervention group and control group in the present study. [24] stated that intakes of iron were lower by $16 \%$ among infants of 6-12 months than children of 13-36 months in an observational study in Brazilian Well Child Clinic. [25] revealed the association between complementary foods and haemoglobin concentration 
among Indian infants. The author stated that there was a positive association between the infants' haemoglobin concentration and fortified baby foods, breast millk and infant formula as well as fruits and vegetables to a lesser extent on the contrary to porridge or gruel. [26] revealed that Iron deficiency (ID) is the most common micronutrient deficiency world-wide and young children are a special risk group because their rapid growth leads to high iron requirements.

The nutrition education on meal frequency, increase in meal frequency during illness and dietary diversity to achieve minimum adequate diet were significantly related to nutrition status of the infants. There were significant differences in the two groups in terms of WHZ and WAZ throughout the period of the study. The effect in the nutrition status of the infants could be linked with the intervention in the feeding practices. This corroborates [27] who stated that there was an association between feeding practices and nutrition status of infants. The findings of [21] in Malawi showed that there was an association between dietary diversity of caregivers and nutrition status of their infants.

There were statistically proved evidences on the effect of the knowledge acquired by the caregivers on the adequate complementary feeding and the nutritional status of the infants in intervention group, especially the acute malnutrition which showed a significant difference in this present study. This was in line with [28] in Ghana; the author stated that there was a significance difference between nutrition status of infants whose mothers had knowledge on complementary feeding practices and those whose mothers had low knowledge. The author stated further that the difference was noted in the WHZ, WAZ and HAZ scores. [29] stated that appropriate weaning practices increased length and weight of children in Ethiopia.

Acute malnutrition was very high among the infants in the control group; this could be due to the poor feeding practices and low knowledge of the caregivers in the control group in this present study. It was noted that the caregivers in the control group could not introduce appropriate complementary feeding during this study period as recommended, due to misconception and false beliefs on appropriate complementary feeding practices. This could be the reason for low energy intake as recorded in this study and it may be the cause for low weight for age and low weight for height. [30] stated that inability of the caregivers to meet the nutrient demand, increased malnutrition among infants. [31] recorded the effect of nutrition education on nutrition status of the infants. The author stated that, despite the health belief of diversifying infants' meals with pulses among mothers in Southern Ethiopia, after offering nutrition education there was a statistical difference in WAZ and WHZ of the infants between the intervention and the control groups. The infants in the intervention group had lower percentage of underweight and wasting than the infants in the control group. The author stated further that improving nutrition knowledge of the mothers improved the nutrition status of the infants.

\section{Acknowledgement}

The authors acknowledge the supports of Owo LGA CHEWs, the research enumerators and Rufus Giwa Polytechnic for technical and personal supports. Also, the author acknowledges community leaders in the research centers for moral support.

\section{Conflicts of interest}

The authors declared no conflict of interest regarding this study.

\section{References}

1. WHO (2010) Indicators for assessing infant and young child feeding practices - Part3: Country profiles, Geneva, Switzerland.

2. UNICEF (2017) State of the world's children: Children in a digital world. pp. 146-177.

3. National Population Commission and ICF International (2014) Nigeria Demographic and Health Survey (NDHS): NPC and ICF International, Nigeria.

4. WHO (2013) Global Strategy for Infant and Young Child Feeding Practices, Geneva health organization, Switzerland.

5. Bhutta ZA, Das JK, Rizvi A, Gaffey MF, Walker N, et al. (2013) Evidencebased interventions for improvement of maternal and child nutrition: what can be done and at what cost? Lancet 382 (9890): 452-477.

6. Sandoval Priego AA, Reyes Morals H, Perez Cuevas D, Abrego Blass R, Orrico Torres ES (2012) Family strategies of life associated with malnutrition in children less than 2 years of age. Salud Publica de Mex 44: 1-9.

7. Arabi M, Frongillo EA, Avula R, Mangasaryan N (2012) Infant and young child feeding in developing countries. Child development 83 (1): 32-45.

8. Ochoke IE, John C, Puoane T (2014) Factors influencing the pattern of Malnutrition among acutely ill children presenting in a tertiary hospital in Nigeria. Nigerian Journal of Paediatrics 41(4): 326-330.

9. National Bureau of Statistics Nigeria (2015-2016) (2015) Demographic Statistics, Case rates of reported notifiable diseases, Nigeria.

10. Mustapha RA, Bolajoko 00 (2013) Growth pattern and nutritional status of under five children in Owo Local Government, Ondo State, Nigeria. IOSR Journal of Pharmacy and Biological Sciences 5(4): 106-109.

11. Bolajoko 00, Ogundahunsi GA (2012) The effect of childcare and feeding practices on the nutritional status of children of market women in Ondo State, Nigeria. IOSR Journal of Pharmacy and Biological Sciences 1(2): 22-24.

12. WHO (2010) Breastfeeding and complementary feeding behaviours ENN.

13. WHO Global Strategy for infants and young child feeding (2003). World Health Organization, Geneva, Switzerland.

14. World Health Assembly (2004) Geneva World Health Organization. Complementary feeding counseling a training course, trainers guide.

15. Oguntona EB, IO Akinyele (1995) Nutrient Composition of Commonly Eaten Foods in Nigeria - Raw Processed and Prepared. Food Basket Foundation Series, Ibadan.

16. FAO (1968) Food Composition Table for use in Africa, United Nation, Rome, Italy.

17.WHO (2006) Child Growth Standards: Methods and Development: Length/height-for-age,weight-forage, weight-for-length, weight-forheight and body mass index-for-age, Geneva, Switzerland, pp. 312.

18. (2015) World Data Atlas Nigeria age of childbearing.

19. Tegegne M, Sileshi S, Benti T, Teshome M, Woldie H (2017) Factors associated with minimal meal frequency and dietary diversity practices among infants and young children in the predominantly agrarian society of Bale zone, Southeast Ethiopia: a community based cross sectional study. Archives of Public Health 75: 53.

20. Kuchenbecker J, Reinbott A, Mtimuni B, Krawinkel MB, Jordan I (2017) Nutrition education improves dietary diversity of children 6-23 months at community-level: Results from a cluster randomized controlled trial in Malawi. PLOS 12(4): e0175216. 
21. Ickles SB, Baguma C, Brahe CA, Myhre JA, Adair LS, et al. (2017) Materna participation in a nutrition education program in Uganda is associated with improved infant and young child feeding practices and feeding knowledge: a post-program comparison study. BMC Nutrition 3: 32-42.

22. UNICEF (2015) Participatory nutrition education catalyst for dietary diversity, Lilongwe, Malawi, East Africa.

23. (2017) National Bureau of Statistics Summary findings of National Nutrition and Health Survey.

24. Francisca Teresa Veneziano Faleiros, Valéria Nóbrega da Silva, Mary de Assis Carvalho, Nilton Carlos Machado (2016) Intake bioavailability, and absorption of iron in infants aged 6 to 36 months: an observational study in a Brazilian Well. Child Clinic Nutrire 41: 10.

25. Prieto Patron A, Hutton ZV, Garg P, Rao S, Eldridge AL, et al. (2017) The Association between Complementary Foods and Hemoglobin Concentrations in Indian Infants. J Hum Nutr Food Sci 5(1): 1105.

26. Domellöf M, Braegger C, Campoy C, et al. (2014) ESPGHAN Committee on Nutrition. Iron requirements of infants and toddlers. J Pediatr Gastroenterol Nutr 58(1): 119-129.
27. Raynor HA, Goff MR, Poole SA, Chen G (2015) Eating Frequency, Food Intake, and Weight: A Systematic Review of Human and Animal Experimental Studies Frontiers in nutrition 2: 38.

28. Saaka, M (2014) Relationship between Mothers' Nutritional Knowledge in Childcare Practices and the Growth of Children Living in Impoverished Rural Communities. J Health Popul Nutr 32 (2): 237-248.

29. Zeleke LB, Gebremichael MW, Adinew YM, AbebeGelaw K (2017) Appropriate Weaning Practice and Associated Factors among Infants and Young Children in Northwest Ethiopia. Journal of Nutrition and Metabolism p. 7.

30. Paintal K, Aguayo VM (2016) Feeding practices for infants and young children during and after common illness. Evidence from South Asia. Matern Child Nutr (Suppl Suppl 1): 39-71.

31. Mulualem D, Henry CJ, Berhanu G, Whiting SJ (2016) The effectiveness of nutrition education: Applying the Health Belief Model in child-feeding practices to use pulses for complementary feeding in Southern Ethiopia. Ecol Food Nutr 55(3): 308-323. 